\title{
KESABARAN CINTA UMMU HABIBAH BERBUAH SURGA
}

\section{St. Hadidjah}

\begin{abstract}
Umm Habibah bint Abu sufyan was Ramlah, her heart has been guided by divine guidance, then she abandoned the religion of her father ( abu sufyan) and she married to a man who does not bow to an idol for sure impending Rasullulah. When the pagan quraysh increased violence to the follower of the prophet, the muslim migrated to habasyah. In the group there ramlah bint abu sufyan along with her husband ubaidillah bin Jaksi al asadi, but unfurnately in a move ubaidillah bin Jaksi Al Asadi apostate he embraced chirtianity. There apostasy husband, umm habibah faced three options, namely, first go back to widowed at migrated place.For the sake of belief whice has been embedded in her heart, umm habibah choose widowed abasyah. Patience in the widowed and Far away from relitives, recorded with Allah Al Migthy. Umm habibah dreamed of being a mother of the faithful, and the dream turned into reality, she actually spoken by the prophed and became one of the mother of the faithful.
\end{abstract}

\section{Keyword :}

\section{PENDAHULUAN}

Cinta adalah sesuatu yang indah yang dianugerahkan sang Khalik ke dalam hati laki-laki dan perempuan. Telah menjadi Sunnatullah bahwa laki-laki mencintai perempuan dan perempuan mencintai laki-laki. Bila cinta sejati telah terpatri di dalam hati seorang laki-laki terhadap perempuan yang telah menawan hatinya, maka cintanya itu akan diperjuankan untuk mendapatkan tambatan hatinya. Begitu juga perempuan akan selalu menanti bilakah pujaan 
hatinya dapat mempersuntingnya,untuk berlayar dalam bahtera rumah tangga menuju pulau bahagia. Cinta sejati yang bulat akan patah bila ada pengkhianatan oleh salah satu pihak. Hati yang patah menjadikan pemiliknya menderita, derita cinta dapat membuat seseorang sakit dan depressi, merana dan berputus asa.

Ummu Habibah Ramlah binti Abu Sufyan menikah dengan Ubaidullah bin Jahsy yang Islam seperti dirinya. Demi cinta sejatinya kepada Ubaidullah bin Jahsy suaminya, Ramlah binti Abu Sofyan rela meninggalkan orang tua dan kampung halamannya pergi berhijrah di bumi Habsy. Namun apa daya, di bumi hijrah Ubaidullah bin Jahsy menukar agamanya dari Islam menjadi Kristen. Dalam keadaan seperti ini, Ummu Habibah berada dipersimpangan tiga. Ada tiga alternatif yang harus dipilih oleh Ummuh Habibah yaitu: Pertama mengikuti suami tercinta untuk sama-sama menjadi Kristiani, Kedua kembali ke Mekkah untuk bersama dengan orang tuanya yang Jahiliyah, Ketiga Menjanda di bumi Hijrah. Terlanjur cinta dengan sang suami Ummu Habibah memilih menjanda. Dalam jandanya, Ummu Habibah mengalami derita cinta yang sangat menekan jiwanya. Namun derita cintanya itu dipasrahkannya kepada Allah swt. Kepasrahannya kepada Allah dalam mengalami derita cintanya dibalas oleh Allah dengan derajat yang tinggi yaitu “ menjadi salah satu Ummul Mukminin" maka kesabaran cinta yang diderita Ummu Habibah berbalas dengan derajat yang tinggi yaitu derajat Ummul Mukminin. Kesabaran atas derita cinta yang menimpah Ummu Habibah berbalas dengan Surga. "Kesabaran Cinta Berbuah Surga”. By. Dra. St. Hadidjah, M.Hum.

\section{PEMBAHASAN}

Ummu Habibah Ramlah binti Abu Sofyan adalah salah satu sayyidah agung yang meninggalkan agama nenek moyangnya dan menjadi seorang muslimah. Ramlah binti Abu Sofyan dinikahi oleh 
Ubaidilah bin Jahsi al Asadi seorang laki-laki hanif yang mempertahankan keyakinannya hingga Nabi Muhammad Saw diutus menjadi Rasullah.

Takkala siksaan kafir Quraisy semakin keras kepada para pengikut Nabi Muhammad Saw dan semakin membahayakan, maka Rasulullah Saw memutuskan menghijrahkan kaum muslimin ke Habasyah. Hal ini terjadi pada tahun ke-5 masa kenabian. Situasi yang genting ini dijawab oleh Allah melalui wahyunya dalam surah az-Zumar (39):10

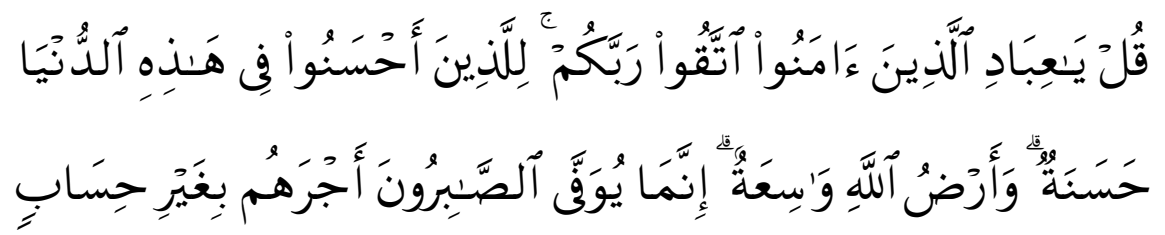

Katakanlah: "Hai hamba-hamba Ku yang beriman. Bertakwalah kepada Tuhanmu". Orang-orang yang berbuat baik di Dunia ini memperoleh kebaikan dan bumi Allah itu adalah luas. Sesungguhnya hanya orang-orang yang bersabarlah yang dicukupkan pahala mereka tanpa batas. ${ }^{1}$

Rombongan kaum muslimin yang berangkat ke Habsyah sekitar 100 orang yang dipimpin oleh Usman bin Affan dan isterinya Ruqaiyyah binti Muhammad Saw, Ja'far bin Abu Thalib, Abdurrahman bin Auf, dan Ummu Habibah binti Abu Sofyan. Segala daya dan upaya dilakukan oleh Abu Sofyan untuk mengembalikan aqidah anaknya kepada aqidah nenek moyangnya tidak berhasil dan akhirnya Ramlah binti Abu Sofyan hijrah ke Habsyi. Di negeri itulah Ramlah binti Abu Sofyan melahirkan seorang anak perempuan dan diberi nama Habibah dank arena itulah dia bergelar Ummu Habibah.

\footnotetext{
${ }^{1}$ Departemen Agama RI, al-Qur'an dan Terjemahannya, Jakarta, 1989, h. 747
} 
Jika di Mekkah Ummu Habibah berhasil mempertahankan imannya sehingga tidak termakan bujukan Abu Sofyan (Ayahnya) untuk kembali ke agama nenek moyangnya, maka di Habsyah iman Ummu Habibah kembali teruji dengan murtadnya Ubaidilah bin Jahsi Masuk ke Agama Kristen. Celakanya, si mustad mencoba membujuk Ummu Habibah agar bersama-sama meninggalkan agama Islam dan Ummu Habibah pun menolaknya. Iman Ummu Habibah kembali teruji oleh kemurtadan sang suami. Sungguh Ummu Habibah ingin agar suaminya tetap dalam imannya yang benar, tetapi Allah SWT berkehendak lain sebagaimana firmannya dalam surah alQashash ayat 56.

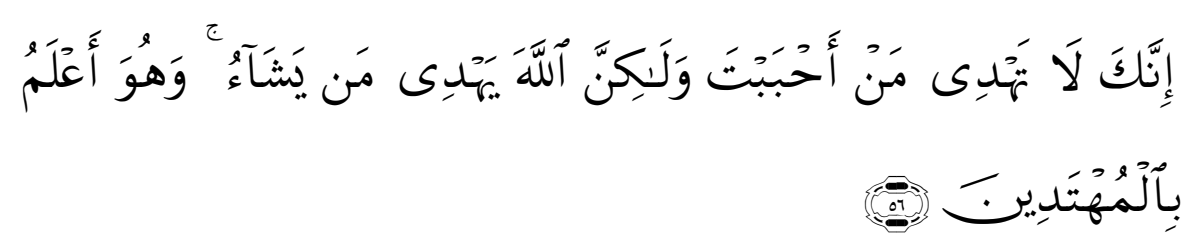

"Hanya Allah-lah yang dapat member taufik kepada hambanya untuk beriman. Sesungguhnya kamu tidak akan dapat member petunjuk kepada orang yang kamu kasihi, tetapi Allah member petunjuk kepada orang yang dikehendakiNya, dan Allah lebih mengetahui orang-orang yang mau menerima petunjuk".

Dari ayat tersebut dapat dipahami bahwa walaupun Ummu Habibah ingin agar suaminya tetap dalam imannya, namun Allah SWT berkuasa untuk member hidayah kepada orang-orang yang dikehendaki-Nya. Murtadnya sang suami menyisahkan tiga opsi berat bagi Ummu Habibah. Pertama, tetap dengan suami yang murtad; kedua, brcerai; ketiga, kembali ke Mekkah. Ternyata Ummu Habibah memilih opsi kedua yaitu bercerai.

${ }^{2}$ Ibid, H. 619 
Hari-hari berlalu di bumi Hijrah dijalani Ummu Habibah dengan penuh kesabaran dia berada dalam dua ujian, yakni jauhnya sanak saudara dan kampung halaman dan ujian karena menjadi seorang janda tanpa seorang pendamping. Walau bagaimana beratnya ujian yang ia derita, tetapi dengan keimanannya yang tulus yang telah Allah karuniakan kepadanya, maupun menghadapi ujian berat tersebut janji Allah kepada orang yang bertakwa akan diberikan jalan keluar dari penderitaan yang dialaminya sebagaimana Allah dalam al-Qur'an Surah Ath-Thalaq ayat 2-3.

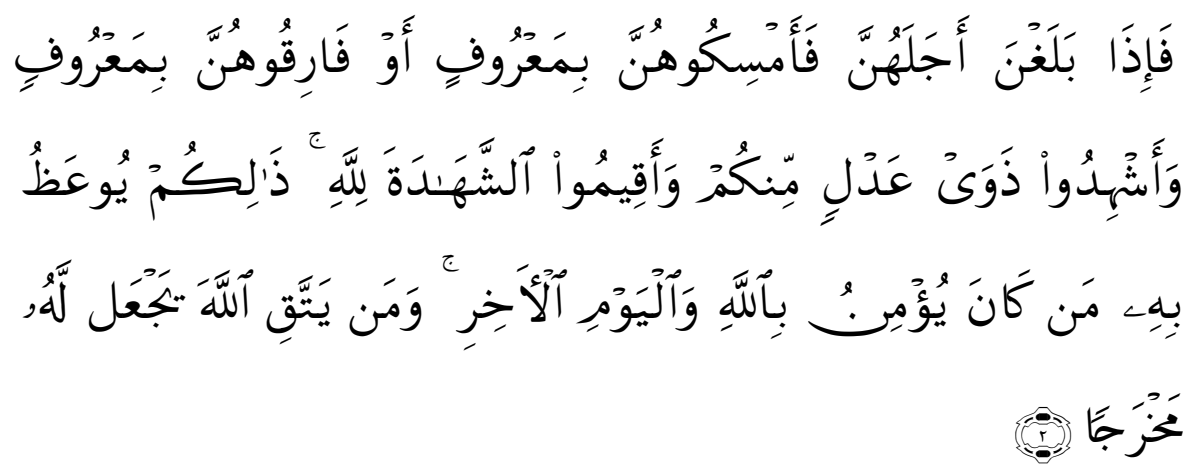

"Hai Nabi, apabila kamu menceraikan isteri-isterimu maka hendaklah kamu ceraikan mereka pada waktu mereka dapat (menghadapi) iddahnya (yang wajar) dan hitunglah waktu iddah itu serta bertakwalah kepada Allah Tuhanmu. Janganlah kamu keluarkan mereka dari rumah mereka dan janganlah mereka (diizinkan) keluar kecuali kalau mereka mengerjakan perbuatan keji yang terang. Itulah hukum-hukum Allah dan barang siapa yang melanggar hukum-hukum Allah, maka sesungguhnya dia telah berbuat zalim terhadap dirinya sebdiri. Kamu tidak mengetahui berengkali Allah mengadakan sesudah itu sesuatu hal yang baru. Apabila mereka telah mendekati akhir iddahnya. Maka rujukilan mereka dengan baik dan persaksikanlah dengan dua orang saksi diantara kamu dan hendaklah kamu tegakkan kesaksian itu karena Allah. 
Demikianlah diberi pengajaran dengan itu yang beriman kepada Allah dan hari akhirat barangsiapa yang bertakwa kepada Allah niscaya Dia akan mengadakan baginya jalan keluar". 3

Setelah Ummu Salama menjalani masa iddah dengan penuh kesabaran, Maka Allah SWT memberikan jalan keluar atas penderitaan yang dialaminya. Adapun jalan keluar yang diberikan oleh Allah SWT kepada Ummu Habibah atas ketabahannya menjalani penderitaan adalah berita gembira melalui mimpi bahwa dia akan menjadi Unimul Mukminin. Dalam mimpinya, Ummu Habibah diseur seseorang:

"wahai Ummul Mukminin, beliau terperanjat bangun karena mimpi tersebut bahwa Rasulullah kelak akan menikahinya". 4

Mimpi Ummu Habibah menjadi Ummul Mukminin terwujud nyata. Rasulullah Saw mengirim surat kepada Najasi lewat sahabat Amr bin Umayya adh-Dhamry sebagai lamaran Rasulullah kepada Ummu Habibah. Rasulullah Swa meminta agar Najasi menyampaikan lamaran itu kepada Ummu Habibah dan sekaligus menjemputnya untuk dating dihadapan Najasi.

Kegembiraan bahwa Rasulullah telah memilih dia diwujudkan dalam bentuk melepaskan perhiasan dan beberapa barang berharganya untuk diberikan kepada budak perempuan utusan Najasi.

Najasi yang saat itu baru saja memeluk Islam melaksanakan nikah kepada Ummu Habibah sebagai wakil dari Rasulullah Saw dengan mahar 400 dinar emas. Orang-orang yang hadir di Majelis

\footnotetext{
${ }^{3} \mathrm{Ibid}$, h. 945

${ }^{4}$ Mahmud Mahdi Al Istambuli dan Mustafa An Nashr Asy Syalibi, Wanita-Wanita Teladan Di Masa Rasulullah, cetakan ketiga, Solo, 2003, hal. 67-68
} 
Najasi tersebut juga diberi dinar dan makanan. Sesudah pernikahannya di Habsya, Ummu Habibah berangkat menuju Madinah.

Kedatangan rombongan Muhajirin dari Habsya tiba di Madinah bersamaan dengan kemenangan kaum muslimin dalam perang Khaibar. Alangka gembiranya Rasulullah Saw pada saat itu karena rombongan yang dari Habsya dating dengan Ummu Habibah, dan kaum muslimin telah memenangkan perang Khaibar.

"Ummu Habibah menempatkan urusan dien pada tempat yang pertama, beliau utamakan akidahnya daripada family. Beliau telah mengumandangkan bahwa loyalitas beliau adalah untuk Allah dan Rasul-Nya bukan untuk seorangpun selain keduanya. Hal itu dibuktikan sikap beliau terhadap ayahnya Abu Sofyan takkala suatu ketika Abu Sofyan masuk ke dalam rumah Ummu Habibah sedangkan beliau ketika itu telah menjadi isteri Rasul di Madinah". 5

Ketika terjadi pelanggaran terhadap salah satu diktum perjanjian Hudaibiyah, Abu Sofyan ayahanda Ummu Habibah memprediksi bahwa kaum muslimin akan marah, karena itu Abu Sofyan dating di Madinah dengan maksud membaharui diktumdiktum yang ada dalam perjanjian tersebut. Tempat pertama yang didatangi oleh Abu Sofyan adalah rumah Ummu Habibah puteri Abu Sofyan yang juga isteri Rasulullah Saw.

Abu Sofyan datang untuk meminta bantuan kepada beliau agar menjadi perantara antara dirinya dengan Rasulullah Saw untuk memperbaharui perjanjian Hudaibiyah yang telah dikhianati sendiri oleh orang-orang musyrik. Ketika Abu Sofyan hendak duduk di atas

${ }^{5}$ Ibid, h. 69 
sebuah alas, Ummu Habibah segera menarik alas tersebut dan melipatnya. Abu Sofyan bertanya kepada Ummu Habibah dengan penuh keheranan.

"Wahai puteriku aku tidak tahu mengapa engkau melarang aku duduk di atas tikar itu, apakah kau melarang aku duduk di atasnya?" Beliau menjawab keberanian dan ketenangan tanpa ada rasa takut terhadap kekuasaan dan kemarahan ayahnya. "Ini adalah tikar Rasulullah Saw, sedangkan engkau adalah orang musyrik yang najis, aku tidak ingin engkau duduk di atas tikar Rasulullah Saw". Abu Sofyan berkata "Demi Allah engkau akan menemui hal buruk sepeninggalku nanti”. "Tidak pernah setelah berpisah denganmu dan selama bersama Rasulullah Saw tidak pernah mendapatkan sesuatu pun kecuali kebaikan dalam segala hal" jawab Ummu Habibah. ${ }^{6}$

Setelah Abu Sofyan wafat, Ummu Habibah hanya berkabung tiga hari lamanya. Sesudah hari ke empat, Ummu Habibah sudah memakai wangi-wangian. Setelah Rasulullah Saw wafat, Ummul Mukminin Ramlah Ummu Habibah tidak pernah meninggalkan rumahnya kecuali untuk shalat, dan tidak pernah meninggalkan Madinah kecuali untuk menunaikan ibadah haji di Mekkah hingga hari wafatnya.

Sungguh beliau berhak menyandang segala kebesaran dan keagungan sebagai Ummul Mukminin, Ummu Habibah. Seandainya para wanita itu seperti beliau niscaya hasilnyapun seperti yang terjadi pada beliau.

\footnotetext{
${ }^{6}$ Ahmad Hatta dkk, The Great Story of Muhammad Saw, Cetakan ke empat, Jakarta. Maghfirah Pustaka, 2014, Hal. 484
} 


\section{KESIMPULAN}

1. Iman yang teguh yang dimiliki Ummu Habibah menjadikan dirinya sabar meniti penderitaan di negeri hijrah.

2. Pohon kesabaran yang dimiliki Ummu Habibah sangat pahit, tetapi buah kesabarannya adalah manis karena kesabaran itulah yang membawanya menjadi Ummul Mukminin.

\section{DAFTAR PUSTAKA}

Ahmad Hatta dkk, The Great Story of Muhammad Saw, Cetakan ke empat, Jakarta. Maghfirah Pustaka, 2014

Departemen Agama RI, al-Qur'an dan Terjemahannya, Jakarta, 1989

Mahmud Mahdi Al Istambuli dan Mustafa An Nashr Asy Syalibi, Wanita-Wanita Teladan Di Masa Rasulullah, cetakan ketiga, Solo, 2003

Trans TV, Khasanah, Media Juni 2015 